Chapter 2

\title{
Multidisciplinary Care of Pregnant Women with Gestational Diabetes Mellitus: Non-Pharmacological Strategies to Improve Maternal and Perinatal Outcomes
}

\author{
Elaine Christine Dantas Moisés \\ Additional information is available at the end of the chapter \\ http://dx.doi.org/10.5772/55295
}

\section{Introduction}

Diabetes Mellitus (DM) is an endocrine disorder characterized by hyperglycemia due to insulin deficiency. This deficiency can be caused by reduced pancreatic production, inadequate release in response to increased carbohydrates or peripheral insulin resistance (ADA, 2009).

\section{Classification}

The first classification for Diabetes Mellitus has been published in 1949 by White Priscilla, categorizing this pathology in classes A, B, C, D, E, F, R, H and T, according to the severity of the disease, age of onset, duration, need for insulin use and the presence or absence of vascular disease arising from the Diabetes Mellitus. This classification is still widely used for predicting complications during pregnancy and is considered as an etiologic and prognostic system (Calderon et al., 2007).

The National Diabetes Data Group (1979) suggested a clinical classification based on the type of Diabetes Mellitus, considering three groups: insulin-dependent Diabetes Mellitus or Type I, Non-insulin-dependent Diabetes mellitus or Type II, and Gestational Diabetes Mellitus (GDM), which is diagnosed during pregnancy. This classification was recommended in 1980 by the World Health Organization Expert Committee on Diabetes Mellitus, being included in the same group of glucose intolerance. This classification was intended to establish a uniform structure for clinical and epidemiological research (Bennett, 1985). 
The American Diabetes Association (ADA) restructured the classification and diagnostic criteria for Diabetes mellitus in 1999, emphasizing its etiology. Subsequently, the ADA (2005) ratified this classification recognized two intermediate stages of the disease, being called pre-diabetes, characterized by impaired glucose tolerance and fasting glucose intolerance (Table 1).

\section{Diabetes mellitus type 1: beta-cell destruction, usually leading to absolute insulin deficiency}

II. Type 2 diabetes mellitus: can vary from primarily due to insulin resistance with relative insulin deficiency to a predominantly secretory defect with insulin resistance

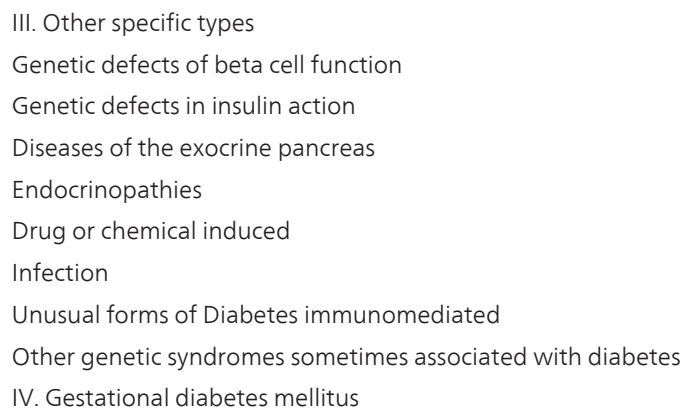

Table 1. Etiological classification of Diabetes mellitus (adapted from ADA, 2005; ADA, 2009).

\section{Epidemiological data on pregnancy}

The dysglycemia is the most common metabolic disorder in pregnancy, but its frequency varies worldwide and among racial and ethnic groups. Broadly in general, the prevalence of dysglycemia during pregnancy can be up to $13 \%$, corresponding to $0.1 \%$ of type 1 diabetes (T1DM), 2-3\% of type 2 diabetes (T2DM) and 12 to 13\% Gestational Diabetes Mellitus, depending on the diagnostic criteria used and the population studied (Hod; Diamant, 1991).

GDM is defined as glucose intolerance of variable severity, which appears or is first diagnosed during pregnancy (ADA, 2009), disappears after childbirth and that does not correspond to a pre-gestational diabetes (ADA, 2011). There has been a significant increase in the number of diagnoses of GDM over time, possibly related to an increase in average maternal weight and age (Getahun et al, 2008). Prevalence also varies according to the method of testing and diagnostic criteria.

It is recommended the early screening of high-risk pregnant women in the first prenatal visit, which allows identifying preexisting diabetes mellitus cases, which should not be erroneously termed as gestational diabetes. Excluding preexisting diabetes mellitus, pregnancy calls for 
the testing of employing glucose overload, from the second trimester of gestation for the diagnosis of GDM. Currently, the American Diabetes Association (ADA, 2011) and the International Association of Diabetes and Pregnancy Study Groups (IADPSG, 2010) recommend 75-g oral glucose tolerance test, with a duration of 2 hours, adopting as diagnostic criteria for GDM cutoff points suggested by the Hyperglycemia and Adverse Pregnancy OutcomesHAPO study (2008), with plasma levels of fasting glucose greater than or equal $92 \mathrm{mg} / \mathrm{dl}$ one hour post glucose load, greater than or equal $180 \mathrm{mg} / \mathrm{dl}$ two hours post glucose load, greater than or equal $153 \mathrm{mg} / \mathrm{dl}$, requiring only a single point change for the diagnosis of GDM. Using the diagnostic criteria proposed by IADPSG, there is detection rate of diabetes during pregnancy in about $18 \%$ of pregnant women.

\section{Glycemic control}

The assessment of glycemic control, through laboratory evaluation of fasting and postprandial blood glucose, supplemented with daily home blood glucose self-monitoring, should be considered every one to two weeks by the treating physician or a member of the multidisciplinary team.

Glycemic control is considered appropriate if blood glucose levels remain within the reference values (fasting less than $95 \mathrm{mg} / \mathrm{dl}$, before meals less than $100 \mathrm{mg} / \mathrm{dl}$, one hour postprandial less than $140 \mathrm{mg}$ / dl, two hours postprandial less than $120 \mathrm{mg} / \mathrm{dl}$ ) and glycosylated hemoglobin test is less than or equal to $6 \%$. The permanence of the blood glucose above the reference values indicates the need for adjustment or inclusion of pharmacological and non-pharmacological therapies (ADA, 2011).

The criterion of excessive fetal growth, through the measurement of fetal abdominal circumference greater than or equal to the 70th percentile on ultrasound between the 29th and 33rd week, can also be used to indicate drug therapy in GDM (Buchanan et al, 1994).

\section{Multidisciplinary care for pregnant women with diabetes mellitus}

During prenatal care, it is essential to focus on providing information to patients about the pathophysiology and prognosis of diabetes mellitus, either pre-existing or gestational. Therefore, consultation should include targeted guidelines for diabetes care, in addition to whole routine prenatal. Its periodicity depends directly on glycemic control, beyond existence and progression of maternal and fetal complications, detected by clinical examination and complementary propaedeutic, whose discussion is not the focus of this chapter.

Poorly controlled DM is often associated with increased risks of adverse maternal and perinatal outcomes. Education and care programs in diabetes, provided by multidisciplinary team in support of the medical staff, acting either alone or associated with pharmacological treatment, may determine changes in the natural history of the disease, improving maternal and perinatal outcomes. 


\section{Nutritionist: Adequacy of food habit to nutritional need}

Initial treatment of GDM and important part of preexisting diabetes treatment consist of nutritional guidance to provide appropriate levels of caloric intake for adequate weight gain during pregnancy, normalization of glycemia, absence of ketones and promote fetal well-being.

Dietary recommendations follow similar patterns to those aimed at the general population. The nutritional prescription constitutes the calculation of caloric intake and mounting the daily menu, in addition to providing basic concepts about nutrition, healthy eating, the food pyramid and food fractionation to the patient in order to arouse attention to the importance of nutrition in pregnancy.

The ideal weight should preferably be achieved prior to pregnancy, since that is the determining factor of the optimum setting of the nutrition prescription throughout gestation cycle. The calculation of caloric value diet and adequate weight gain can be made according to the idealized tables for this purpose (table 2), based on the Body Mass Index prior to pregnancy, frequency and intensity of physical exercises and fetal growth pattern (Kaiser, Allen, 2008).

\begin{tabular}{|c|c|c|c|c|}
\hline Nutritional status & $\begin{array}{l}\text { BMI prior to } \\
\text { pregnancy } \\
\left(\mathrm{Kg} / \mathrm{m}^{2}\right)\end{array}$ & $\begin{array}{l}\text { Total weight gain } \\
\text { in the first } \\
\text { trimester }(\mathrm{Kg})\end{array}$ & $\begin{array}{l}\text { Weekly weight gain in } \\
\text { the second and third } \\
\text { trimesters }(\mathrm{Kg})\end{array}$ & $\begin{array}{c}\text { Total weight gain } \\
\text { in the pregnancy } \\
(\mathrm{Kg})\end{array}$ \\
\hline Underweight & $<18.5$ & 2.3 & 0.5 & $12.5-18$ \\
\hline Normal Weight & $18.5-24.9$ & 1.6 & 0.4 & $11.5-16$ \\
\hline Overweight & $25.0-29.9$ & 0.9 & 0.3 & $7-11.5$ \\
\hline Obese & $\geq 30.0$ & - & 0.3 & $5-9$ \\
\hline
\end{tabular}

Kg: kilogram

$\mathrm{Kg} / \mathrm{m}^{2}$ : kilograms per square meter

BMI: Body Mass Index

Table 2. Recommendation for total gain weight during pregnancy according to the Body Mass Index (BMI) before pregnancy (adapted from Kuehn, 2009).

In clinical practice, for women with BMI below $18.5 \mathrm{~kg} / \mathrm{m}^{2}$, the prescription of caloric intake can be up to $40 \mathrm{kcal} / \mathrm{kg} /$ day; for women with BMI between 18.5 and $24.9 \mathrm{~kg} / \mathrm{m}^{2}$, energy 
intake should be $30 \mathrm{kcal} / \mathrm{kg}$ / day; for women who are overweight, the caloric supply is 22 to $25 \mathrm{kcal} / \mathrm{kg} / \mathrm{day}$; for the morbid obese women the caloric prescription must be from 12 to 14 $\mathrm{kcal} / \mathrm{kg} /$ day.

The diet should be planned throughout the day, being split into three large meals and three snacks (ADA, 2004), being the carbohydrate intake distributed between them, aiming to prevent postprandial hyperglycemia. The nutritional requirement of carbohydrates should be restricted to less than $40 \%$ of total daily calories, with the remainder distributed among proteins (15\% to $20 \%$ of total calories per day, at least $1.1 \mathrm{~g} / \mathrm{kg} /$ day) and fats (30\% to $40 \%$ of total calories per day). The adjustment of the postprandial insulin dose can be done by calculating the carbohydrate content of each meal.

Non-nutritive artificial sweeteners such as aspartame, saccharin, acesulfame-K and sucralose can be used sparingly, aiding the adaptation of taste to food (ADA, 2004).

\section{Physical educator and therapist: Physical activity as a strategy for prevention and adjuvant treatment}

Physical activity reduces insulin resistance, facilitating peripheral glucose utilization with consequent improvement of glycemic control while also helping to control weight gain during pregnancy (Reader, 2007).

The recommended exercise prescription is low-impact physical activity, ideally being practiced daily for at least 30 minutes, which can be divided into three sessions of ten minutes each, keeping levels not exceeding $50 \%$ of the aerobic capacity of the patient (table 3 ).

Parameter Programa

Frequency $\quad 3$ to 4 days / week

Intensity Variable (according to the previous fitness)

Duration Initially 15 minutes with gradual increase up to a maximum of 30 minutes / session

$\begin{array}{ll}\text { Modality } & \text { Low impact aerobic } \\ \text { Strength training and endurance }\end{array}$

Table 3. Prescription of exercise during pregnancy (adapted from Davies et al, 2003). 
It constitutes safe method to be used during pregnancy (Szymanski, Satin, 2012). Some precautions should be observed in handling (Ferraro, Gaudet, Adamo, 2012), such as starting the physical activity sessions preferably after meals, avoiding beginning if the blood glucose is below $60 \mathrm{mg} / \mathrm{dL}$ or above $250 \mathrm{mg} / \mathrm{dL}$ (Artal, 2003). The practice of physical exercises during pregnancy is also contraindicated in cases of obstetric complications and / or concomitant medical complications, as reported in Table 4.

Obstetric contraindications

Previous Miscarriage or preterm childbirth

Cervical incompetence

Premature rupture of membranes

Preterm labor

Intrauterine growth restriction

Multiple pregnancy: (two fetuses after $28^{\text {th }}$ week or three

or more fetuses at any gestational age)

Placenta previa after $28^{\text {th }}$ week

Persistent bleeding in the second and / or third trimesters

\section{Clinical contraindications}

Cardiovascular disease

Hypertensive disease

Respiratory disease

Anemia $(\mathrm{Hb}<10 \mathrm{~g} / \mathrm{dl})$

Malnutrition or eating disorder

Uncontrolled Diabetes Mellitus Type 1

Decompensated thyroid disease

$\mathrm{Hb}$ : hemoglobin

g/dl: grams per deciliter

Table 4. Contraindications to physical exercise during pregnancy (adapted from Davies et al, 2003).

\section{Psychologist: Emotional support as a strategy for treatment adherence}

Pregnancy, by itself, constitutes a period marked by several changes in women's lives, involving social, biological, marital and psychological changes, which are aggravated because of the occurrence of clinical and / or obstetric conditions that may potentially alter the maternal and / or fetal outcomes. These changes may act as stressors and may interfere in a positively or negatively way in adherence to the proposed treatment.

Psychological care has an evaluative component and, on the other hand, it also has an instructional feature that serves as a basis for reflection and construction of behavior in the situation experienced.

The initial characterization of the social, emotional and psychological aspects involving a pregnant woman can be accomplished through evaluation instruments (Cohen, Kamarck, Mermelstein, 1983; Zigmond, Snaith, 1983; Sherbourne, Stewart, 1991; Herrmann, 1997).

Regarding psychological intervention approach should initially focus on the demands related to pregnancy and Diabetes Mellitus brought by the patient herself and, subsequently, expand the focus to the instructional aspect, based on the information acquired. The understanding of the whole process of health care and the benefits of the proposed interventions are the basis 
for building the strategy of treatment adherence, particularly with regard to diet (Gardner et al, 2012).

\section{Nurse: Combination of communication strategies and training techniques}

Nursing staff has fundamental integrator role in the care program for pregnant women with diabetes mellitus. It features functions such as consolidation of primary communication channel created by other professionals, technical training of specialized care and monitoring of metabolic control of patient.

Different communication strategies can be adopted in order to achieve success in providing guidance and establishing appropriate relationship with patients, that allow effective training techniques of glycemic control monitoring. The establishment of this open channel of communication between the patient and nursing staff provides another opportunity to solidify concepts, in addition to allowing the sharing of anxieties and doubts, minimized by this team of professionals, collaborating to treatment adherence (Furskog et al, 2012; Mendelson et al, 2008; Persson et al, 2011).

Active and constant participation of nursing staff in the monitoring of glycemic control can determine the establishment of the patient's attention to self-care and, consequently, the drop in rates of adverse events, improving maternal-fetal prognosis (Ferrara et al, 2012)

\section{Social worker: Creation of favorable environmental conditions for the treatment}

The Social Services is responsible for providing guidance on social rights and social security, as well as duties related to treatment. Actions related to insertion of pregnant women in social support networks can facilitate access to certain resources, which allows better adherence to treatment and success of such proposals.

The social worker must also foster opportunities for discussion in order to create conditions for pregnant women develop their critical capacity as subjects of rights.

Reviews regarding the effectiveness of interventions offered to women during pregnancy who have been identified with social risk factors in relation to the development of depression and adherence to clinical follow-up are under development in literature (Kenyon et al, 2012).

\section{Multidisciplinary group: Strategy of sharing experiences}

Considering that the behavior of a pregnant woman can act as a multiplier of information and influence the conduct of another patient, it is possible to use pregnant women with adequate 
adhesion to treatment as a reference to be followed. In this context, multidisciplinary care with groups of diabetic pregnant women can be an effective complementary strategy to individual assistance.

\section{Acknowledgements}

To the multidisciplinary team of Clinical Hospital of Faculty of Medicine of Ribeirão Preto, University of São Paulo:

Psychologist: Juliana Caseiro

Social Worker: Renata Cecílio

Nutritionist: Daniella Cristina Fernandes da Silva

Head nurse: Ana Lúcia Moreira Fernandes

\section{Author details}

Elaine Christine Dantas Moisés

Department of Gynecology and Obstetrics, Faculty of Medicine of Ribeirão Preto, University of São Paulo, Brazil

\section{References}

[1] American Diabetes Association (2005). Diagnosis and Classification of Diabetes Mellitus. Diabetes Care28 (Suppl 1):SS42., 37.

[2] American Diabetes Association (2009). Diagnosis and Classification of Diabetes Mellitus. Diabetes Care 32 (Suppl 1): SS67., 62.

[3] American Diabetes Association- ReportsPosition of the American Dietetic Association: use of nutritive and nonnutritive sweeteners (2004). J Am Diet Assoc., 255-275.

[4] American Diabetes Association (2011). Standards of medical care in diabetes-2011. Diabetes Care 34 (Suppl 1): SS61., 11.

[5] Artal, R. (2003). Exercise: the alternative therapeutic intervention for gestational diabetes. Clin Obstet Gynecol, 46(2), 479-487.

[6] Bennett, P. H. (1985). Basis of the present classification of Diabetes. Adv Exp Med Biol., 189, 17-29. 
[7] Buchanan, T, Kjos, S. L, \& Montoro, M. N. Wu PYK, Madrilejo NG, Gonzales M (1994). Use of fetal ultrasound to select metabolic therapy for pregnancies complicated by mild diabetes. Diabetes Care, 17, 275-283.

[8] Calderon IMPKerche LTRL, Damasceno DC, Rudge MVC (2007). Diabetes and Pregnancy: an Update of the Problem. ARBS Annu Rev Biomed Sci, 9, 1-11.

[9] Cohen, S, Kamarck, T, \& Mermelstein, R. (1983). A global measure of perceived stress. J Health Soc Behav, 24(4), 385-396.

[10] Davies, G. A, Wolfe, L. A, \& Mottola, M. F. MacKinnon C; Society of Obstetricians and gynecologists of Canada, SOGC Clinical Practice Obstetrics Committee (2003). Joint SOGC/CSEP clinical practice guideline: exercise in pregnancy and the postpartum period. Can J Appl Physiol, 28(3), 330-341.

[11] Ferrara, A, Hedderson, M. M, Ching, J, Kim, C, Peng, T, \& Crites, Y. M. (2012). Referral to telephonic nurse management improves outcomes in women with gestational diabetes. Am J Obstet Gynecol206(6):491.e, 1-5.

[12] Ferraro, Z. M, Gaudet, L, \& Adamo, K. B. (2012). The potential impact of physical activity during pregnancy on maternal and neonatal outcomes.Obstet Gynecol Surv, 67(2), 99-110.

[13] Furskog Risa C, Friberg F, Lidén E (2012). Experts' encounters in antenatal diabetes care: a descriptive study of verbal communication in midwife-led consultations. Nurs Res Pract2012:121360

[14] Gardner, B, Croker, H, Barr, S, Briley, A, Poston, L, \& Wardle, J. UPBEAT Trial (2012). Psychological predictors of dietary intentions in pregnancy. J Hum Nutr Diet, 25(4), 345-353.

[15] Getahun, D, Nath, C, Ananth, C. V, Chavez, M. R, \& Smulian, J. C. (2008). Gestational diabetes in the United States: temporal trends 1989 through 2004. Am J Obstet Gynecol 198(5):525.e, 1-5.

[16] HAPO Study Cooperative Research GroupMetzger BE, Lowe LP, Dyer AR, Trimble ER, Chaovarindr U, Coustan DR, Hadden DR, McCance DR, Hod M, McIntyre HD, Oats JJ, Persson B, Rogers MS, Sacks DA ((2008). Hyperglycemia and adverse pregnancy outcomes. N Engl J Med , 358(19), 1991-2002.

[17] Herrmann, C. (1997). International experiences with the Hospital Anxiety and Depression Scale--a review of validation data and clinical results. J Psychosom Res, 42(1), 17-41.

[18] Hod, M, \& Diamant, Y. Z. (1991). Diabetes in pregnancy. Norbert Freinkel Memorial Issue. Isr J Med Sci, 27, 421-532.

[19] International Association of Diabetes and Pregnancy Study Groups Consensus PanelMetzger BE, Gabbe SG, Persson B, Buchanan TA, Catalano PA, Damm P, Dyer AR, Leiva A, Hod M, Kitzmiler JL, Lowe LP, McIntyre HD, Oats JJ, Omori Y, Schmidt MI 
((2010). International association of diabetes and pregnancy study groups recommendations on the diagnosis and classification of hyperglycemia in pregnancy. Diabetes Care, 33(3), 676-682.

[20] Kaiser, L, \& Allen, L. H. (2008). Position of the American Dietetic Association: nutrition and lifestyle for a healthy pregnancy outcome. J Am Diet Assoc, 108(3), 553-561.

[21] Kenyon, S, Jolly, K, Hemming, K, Ingram, L, Gale, N, Dann, S. A, \& Chambers, J. MacArthur C (2012). Evaluation of Lay Support in Pregnant women with Social risk (ELSIPS): a randomised controlled trial. BMC Pregnancy Childbirth12:11.

[22] Kuehn, B. M. (2009). Guideline for pregnancy weight gain offers targets for obese women. JAMA, 302(3), 241-242.

[23] Mendelson, S. G, Mcneese-smith, D, Koniak-griffin, D, Nyamathi, A, \& Lu, M. C. parish nurse intervention program for Mexican American women with gestational diabetes. J Obstet Gynecol Neonatal Nurs, 37(4), 415-425.

[24] National Academy of Sciences Institute of Medicine, Food and Nutrition Board, Committee on Nutritional Status During Pregnancy and Lactation, Subcommittee for a Clinical Application Guide: Nutrition During Pregnancy and Lactation: An Implementation Guide. Washington, D.C., National Academies Press (1992).

[25] Persson, M, Hörnsten, A, Winkvist, A, \& Mogren, I. (2011). Mission impossible"? Midwives' experiences counseling pregnant women with gestational diabetes mellitus. Patient Educ Couns, 84(1), 78-83.

[26] Sherbourne, C. D, \& Stewart, A. L. (1991). The MOS social support survey. Soc Sci Med, 32(6), 705-14.

[27] Szymanski, L. M, \& Satin, A. J. (2012). Exercise during pregnancy: fetal responses to current public health guidelines. Obstet Gynecol, 119(3), 603-10.

[28] Zigmond, A. S, \& Snaith, R. P. (1983). The hospital anxiety and depression scale. Acta Psychiatr Scand, 67(6), 361-70. 